\title{
Potensi Zat Warna Dari Ekstrak Etanol Kayu Sappang Sebagai KalorimetriAnion
}

\author{
Nurmala Sari ${ }^{*}$, Rachma $^{2}$, Santi $^{1}$ \\ ${ }^{1}$ STIKes Mega Rezky Makassar, ${ }^{2}$ Politeknik Akademi Teknik Industri Makassar \\ email: nurmalasari.chemist@gmail.com
}

\begin{abstract}
Dye from Sappang Tree has been isolated using ethanol as a solvent. Braziline is one of the chemical compound found in the ethanol extract. The Compound can be used as anion calorimethric due to their active sites of hydroxyl and chromophore groups. Dyes from sappang tree has been tested on $10 \mathrm{~g}$ of several types of saturated anions (carbonate, sulfate, phosphate, cyanide, acetate, borax, nitrite, chloride, bromide, and iodide). The results of the tests show that the color of the dye from changes in carbonate, phosphate, cyanide, acetate, nitrite, and hydroxyl. Spectrophotometer UV/Vis is used to detect the limit of cyanide anion. Metanol and acetone show positive results on the dye in cyanide anion. Detection limit of braziline is $3 \times 10^{-4} \mathrm{M}$. By addition of cyanide anion, the dye has detection limit at $1 \times 10^{-4} \mathrm{M}$.
\end{abstract}

Keywords : anion sensor, brazilin, detection limit, ionochromic, Sappang Tree dye

\section{PENDAHUluan}

Limbah industri merupakan salah satu masalah yang saat ini belum dapat diatasi oleh pemerintah. Pembuangan limbah disembarang tempat khususnya didaerah perairan dapat mencemari lingkungan bahkan dapat berefek negatif bagi makhluk hidup khususnya pada manusia. Salah satu kandungan limbah yang cukup berbahaya apabila melewati ambang batas yaitu senyawa anion. Senyawa anion seperti anion sianida, anion fluorida dan anion karbonat merupakan anion yang sering menyebabkan terjadinya pencemaran karena sebagian besar dihasilkan oleh limbah industry (Afkahmi \& Nahid, 2007; Marini et.al., 2010; Zhang \& Suslick, 2005).

Anion sianida dapat memberikan dampak negatif bagi kesehatan apabila tidak sengaja dikonsumsi seperti dapat menyebabkan muntah, diare, sakit perut yang berkepanjangan bahkan dapat menyebabkan kematian (Zhang, \& Suslick., 2005). Maka dari itu perlu dilakukan penelitian yang dapat mengindentifikasi adanya pencemaran anion. Dalam penelitian ini dilakukan identifikasi anion dengan cara kalorimetri berdasarkan konsep kemosensor.

Kemosensor merupakan suatu proses yang dapat memperlihatkan adanya suatu senyawa atau ion pada sampel maupun pada senyawa kompleks (McDonagh, Burke \& Craith, 2008). Metode deteksi adanya senyawa atau ion dapat dilakukan dengan metode titrimetri, volumetri, potensiometri, elektrokimia dan kromatografi ion. Metode-metode tersebut merupakan metode

Al-Kimia | Volume 5 Nomor 22017 || 136 
yang memerlukan waktu analisis yang relatif lama, melibatkan alat instrumendengan batas deteksi yang tinggi dan membutuhkan investasi peralatan yang mahal (Xu, et.al., 2010). Oleh karena itu perlu dikembangkan suatu metode pendeteksi yang murah, efisiensi, tanpa membutuhkan alat instrumen, dan dapat dilihat dengan mata telanjang. Metode yang dimaksud merupakan metode kolorimetri yaitu suatu metode yang terjadi karena adanya perubahan warna akibat adanya ion/senyawa (Satheshkumar, et.al., 2014). Senyawa brazilin pada kayu sappang (K. Sappang) memiliki gugus hidroksil sebagai sisi aktif dan pasangan elektron yang terkonjugasi sebagai gugus kromofor sehingga berpotensi sebagai senyawa sensor anion.

Secara kimia, semua antosianin merupakan turunan dari kation flavilium $(3,5,7,4$ ' tetrahidroksiflavilium) yang merupakan struktur dasar dari antosianidin (Timberlake \& Bridle, 1997).

Menurut Indriani (2003) Brazilin $\left(\mathrm{C}_{16} \mathrm{H}_{14} \mathrm{O}_{5}\right)$ adalah kristal berwarna kuning yang merupakan pigmen warna pada K. Sappang Asam tidak berpengaruh terhadap larutan brazilin, tetapi alkali dapat membuatnya bertambah merah. Eter dan alkohol menimbulkan warna kuning pucat terhadap larutan brazilin. Brazilin akan cepat membentuk warna merah ini disebabkan oleh terbentuknya brazilein. Brazilin jika teroksidasi akan menghasilkan senyawa brazilein yang berwarna merah kecoklatan dan dapat larut dalam air. Rumus struktur untuk brazilein dan brazilin dapat dilihat pada Gambar 1 .
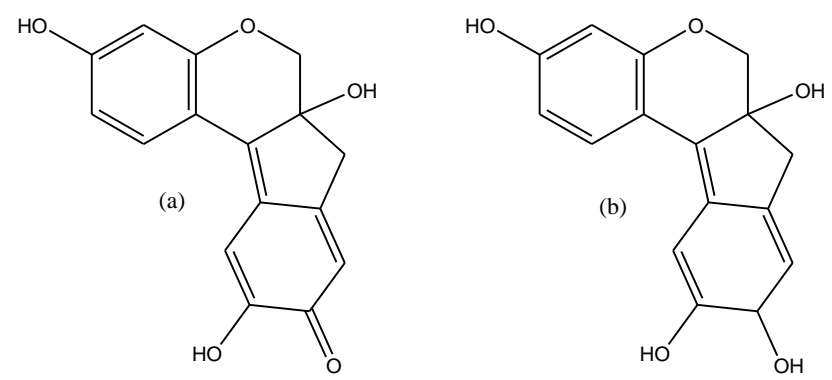

Gambar 1. Struktur senyawa brazilein (a) dan Brazilin (b)

\section{METODE PENELITIAN}

\section{Alat}

Peralatan yang digunakan untuk penelitian ini meliputi: seperangkat alat gelas laboratorium, timbangan analitik (Libror EB-330 Shimadzu), desikator, Instrumentasi kimia yang digunakan adalah lampu UV 254 dan 366 nm (Camac UV-Cabinet II), Spektrofotometer infra merah IR,Shimadzu Prestige-21).

Al-Kimia | Volume 5 Nomor 22017 || 137 


\section{Bahan}

Bahan yang digunakan dalam penelitian ini meliputi serbuk kayu sappang, etanol, metanol, aseton, natrium sulfat $\left(\mathrm{Na}_{2} \mathrm{SO}_{4}\right)$ anhidrat, natrium nitrit $\left(\mathrm{NaNO}_{2}\right)$, natrium boraks $\left(\mathrm{Na}_{2} \mathrm{~B}_{4} \mathrm{O}_{7}\right)$, natrium bromida $(\mathrm{NaBr})$, kalium sianida $(\mathrm{KCN})$, natrium asetat $\left(\mathrm{CH}_{3} \mathrm{COONa}\right)$, natrium klorida $(\mathrm{NaCl})$, natrium karbonat $\left(\mathrm{Na}_{2} \mathrm{CO}_{3}\right)$, kalium iodida $(\mathrm{KI})$, natrium hidrogen fosfat $\left(\mathrm{NaH}_{2} \mathrm{PO}_{4}\right)$, Semua bahan kimia yang digunakan mempunyai kualitas p.a Merck.

\section{Prosedur Kerja}

Preparasi sampel

K. Sappang dikeringkan kemudian dipotong-potong kecil-kecil. Selanjutnya digiling sampai membentuk serbuk.

\section{Ekstaksi Zat Warna Pada Kayu Ssappang}

Pada penelitian ini bahan dalam bentuk serbuk (K. Sappang) yang dimaserasi dengan etanol selama 1x24 jam sebanyak 3 kali. Maserat yang dihasilkan dikeringkan dengan menggunakan evaporator.

\section{Identifikasi}

Pada tahap ini ekstrak etanol yang diperoleh dianalisis dengan menggunakan spektrofotometer IR untuk mengetahui gugus fungsi yang berada pada senyawa zat warna.

\section{Uji solvatochromic terhadap zat warna ekstrak Kayu Sappang}

Uji solvatochromic dilakukan dengan melarutkan ekstrak etanol K. Sappang dalam pelarut metanol sebagai pelarut protik $\left(1 \times 10^{-3} \mathrm{M}\right)$ dan pelarut aseton sebagai pelarut aprotik. Selanjutnya dilakukan analisis spektrofotometer UV-Vis untuk mengetahui panjang gelombang dari setiap senyawa tersebut baik dalam pelarut metanol maupun dalam pelarut aseton.

Uji terhadap zat warna ekstrak etanol Kayu Sappang sebagai senyawa ionochromic

Uji senyawa ionochromic dilakukan dengan meneteskan 2 tetes larutan jenuh $\mathrm{NaCl}, \mathrm{NaBr}$, $\mathrm{KI}, \mathrm{Na}_{2} \mathrm{SO}_{4}, \mathrm{Na}_{2} \mathrm{CO}_{3}, \mathrm{Na}_{2} \mathrm{HPO}_{4}, \mathrm{KCN}, \mathrm{NaNO}_{2}, \mathrm{Na}_{2} \mathrm{~B}_{4} \mathrm{O}_{7}$ dan $\mathrm{CH}_{3} \mathrm{COONa}$ ke dalam ekstrak etanol K. Sappang $\left(1 \times 10^{-3} \mathrm{M}\right.$ dalam metanol dan aseton). Perubahan warna yang terjadi pada larutan dicatat.

\section{Uji limit deteksi terhadap zat warna ekstrak etanol Kayu Sappang sebagai sensor anion sianida}

Larutan diteteskan ke dalam ekstrak etanol K. Sappang $1 \times 10^{-4} \mathrm{M}$ dalam metanol, atau aseton) dengan berbagai konsentrasi untuk menentukan titik ekuivalen dari anion sianida 
terhadap ekstrak etanol kayu sappang. Perubahan warna yang terjadi pada larutan dicatat dan ditentukan limit deteksinya berdasarkan hasil pengukuran UV-Vis.

\section{HASIL DAN PEMBAHASAN}

\section{Isolasi dan indentifilasi zat warna}

K. Sappang sebanyak 72 g dimaserasi dengan etanol kemudian dievaporasi dan menghasilkan bubuk berwarna merah sebanyak $510 \mathrm{mg}$, Karakterisasi senyawa hasil isolasi, dianalisis dengan menggunakan FT-IR (Gambar 2). Karakterisasi senyawa isolasi dari zat warna kayu sappang dari data spektrum IR ( $\mathrm{KBr}$ ) yang menunjukkan bahwa adanya gugus $\mathrm{OH}$ pada bilangan gelombang $3385 \mathrm{~cm}^{-1}$ dengan didukung oleh adanyavibrasi ulur ikatan C-O pada 1109 dan $1026 \mathrm{~cm}^{-1}$. Serapan pada $2924 \mathrm{~cm}^{-1}$ yang merupakan $\mathrm{Csp}^{2}-\mathrm{H}$ yang didukung dengan adanya $\mathrm{C}=\mathrm{C}$ aromatik pada daerah serapan pada $1504 \mathrm{~cm}^{-1}$. Sehingga diindikasikan bahwa maserat zat warna pada kayu sappang mengandung senyawa brazilin (Gambar 3).

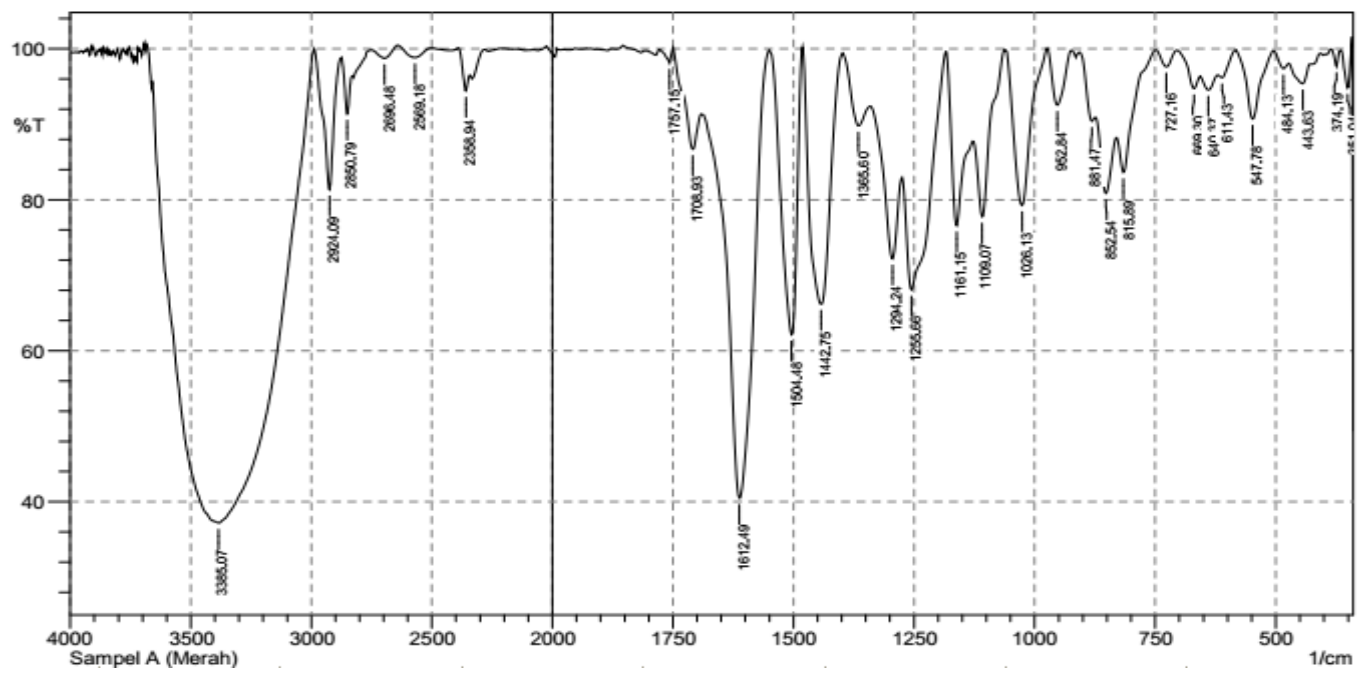

Gambar 2. Spektrum FT-IR zat warna kayu Sappang<smiles>Oc1ccc2c(c1)OC[C@]1(O)Cc3cc(O)c(O)cc3[C@H]21</smiles>

Gambar 3. Struktur Senyawa Brazilin

Al-Kimia | Volume 5 Nomor 22017 | 139 


\section{Uji Solvatochromic Terhadap Zat Warna Kayu Sappang}

Zat warna kayu sappang (brazilin) memiliki warna yang berbeda dalam pelarut metanol maupun aseton. Konsentrasi $1 \times 10^{-3} \mathrm{M}$ yang dilarutkan dalam pelarut metanol menunjukkan zat warna kayu sappang (brazilin) berwarna oranye dengan panjang gelombang $360 \mathrm{~nm}$ dan zat warna kayu sappang (brazilin) dengan konsentrasi $1 \times 10^{-3} \mathrm{M}$ memperlihatkan warna kuning dengan panjang gelombang $356 \mathrm{~nm}$ (Gambar 4).
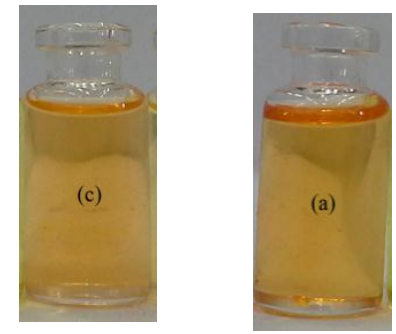

Gambar 4. Zat warna kayu sappang dalam pelarut metanol (a) dan aseton (c).

Hasil uji solvatochromic menunjukkan bahwa zat warna kayu sappang (brazilin) dalam pelarut metanol dan aseton mengalami peristiwa solvatochromismpositif. Metanol dan Aseton memiliki keadaan dasar dan keadaan tereksitasi yang berbeda akibat dari kepolaran pelarut metanol atau aseton sehingga pada pelarut metanol dan aseton mengalami pergeseran hipsokromik atau pergeseran batokromik (Reichardt, 1994)

\section{Uji Ionochromic Zat Warna Kayu Sappang}

Zat warna kayu sappang (brazilin) dalam konsentrasi $1 \times 10^{-3} \mathrm{M}$ dilarutkan dalam pelarut metanol (Gambar 5) atau aseton (Gambar 6). Kemudian larutan senyawa tersebut ditambahkan 2 tetes larutan anion dari larutan jenuh garam seperti garam fosfat, garam asetat, garam karbonat, garam sulfat, garam sianida, garam boraks, garam nitrit, garam klorida, garam bromida garam iodida dan natrium hidroksida.

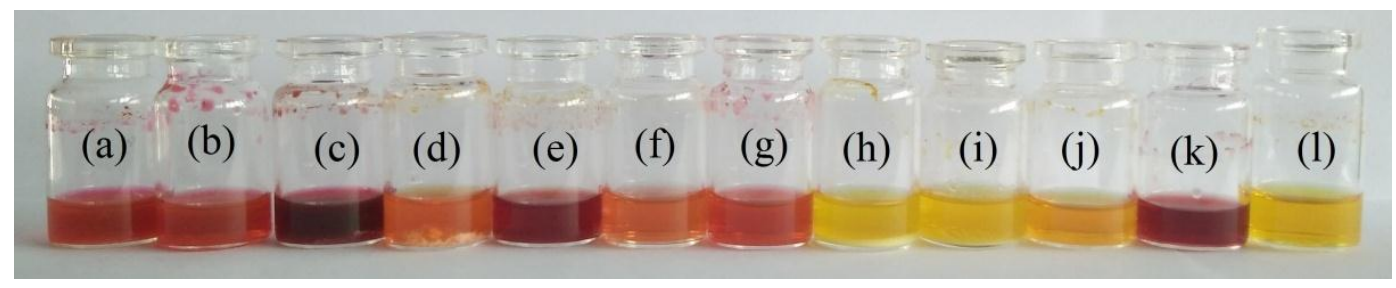

Gambar 5. Hasil uji ionochromic terhadap zat warna kayu sappang (brazilin $1 \times 10^{-3} \mathrm{M}$ dalam metanol). a) $\mathrm{HPO}_{4}{ }^{2-}$, b) $\mathrm{CH}_{3} \mathrm{COO}^{-}$, c) $\mathrm{CO}_{3}{ }^{-}$, d) $\mathrm{SO}_{4}{ }^{2-}$, e) $\mathrm{CN}^{-}$, f) $\mathrm{B}_{4} \mathrm{O}_{7}{ }^{2-}$, g) $\mathrm{NO}_{2}^{-}$, h) $\mathrm{I}^{-}$, i) $\mathrm{Br}^{-}$, j) $\left.\mathrm{Cl}^{-}, \mathrm{k}\right) \mathrm{OH}^{-}$dan 1) Standar 


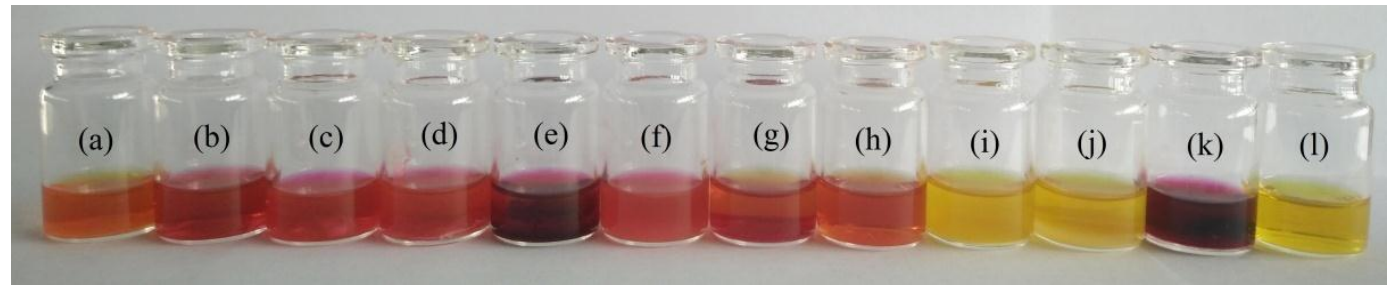

Gambar 6. Hasil uji ionochromic terhadap zat warna kayu sappang(brazilin $1 \times 10^{-3} \mathrm{M}$ dalam aseton). a) $\mathrm{HPO}_{4}{ }^{2-}$, b) $\mathrm{CH}_{3} \mathrm{COO}^{-}$, c) $\mathrm{CO}_{3}{ }^{-}$, d) $\mathrm{SO}_{4}{ }^{2-}$, e) $\mathrm{CN}^{-}$, f) $\mathrm{B}_{4} \mathrm{O}_{7}{ }^{2-}$, g) $\mathrm{NO}_{2}{ }^{-}$, h) $\mathrm{I}^{-}$, i) $\mathrm{Br}^{-}$, j) $\left.\mathrm{Cl}^{-}, \mathrm{k}\right) \mathrm{OH}^{-}$dan l) Standar

Hasil Uji ionochromic dengan menggunakan pelarut metanol memperlihatkan bahwa zat warna K. Sappang (brazilin) mengalami perubahan warna dari warna oranye menjadi warna merah apabila diinteraksikan dengan,anion fosfat, anion asetat, dan anion nitrit. Zat warna tersebut berinteraksi dengan anion karbonat, anion sianida dan anion hidroksil menjadi warna merah keunguan sedangkan untuk anion sulfat, anion boraks, anion iodide, anion klorida dan anion bromida mengalami perubahan warna yang kurang signifikan. Hal tersebut disebabkan karena anion sulfat, anion boraks, anion iodide, anion klorida dan anion bromida kemungkinan dapat berinteraksi dengan zat warna K. Sappang (brazilin) melalui ikatan hidrogen yang menunjukkan perbedaan warna tidak begitu spesifik dengan warna sebelumnya (Alghiri, 2010). Sedangkan anion fosfat, anion asetat, anion nitrit, anion karbonat, anion sianida dan anion hidroksil memperlihatkan perubahan dari warna kuning menjadi warna merah bahkan sampai membentuk warna merah keunguan. Hal tersebut disebabkan karena anion tersebut memiliki interaksi yang lebih kuat dan menyebabkan terjadinya deprotonasi dibandingkan dengan anion sianida, anion klorida dan anion iodida yang hanya terjadi ikatan hidrogen saja (Alghiri, 2010). Akibat interaksi dengan anion tersebut, elektron pada senyawa brazilin pasa zat warna kayu sappang mengalami konjugasi yang cukup panjang dan akan menghasilkan warna dengan panjang gelombang yang lebih panjang dibandingkan interaksi dengan anion yang mengalami perubahan warna menjadi jingga.

Pada pelarut aseton terjadi perubahan yang warna yang lebih signifikan pada anion sulfat, anion boraks, anion iodida yaitu dari warna oranye menjadi warna merah, serta anion sianida dan anion hidroksil yang semakin pekat. Perubahan pelarut dari metanol ke aseton menyebabkan perubahan sensitifitas dan selektifitas anion. Mengingat metanol sebagai pelarut polar yang protik sedangkan aseton sebagai pelarut polar aprotik maka faktor solvasi pelarut terhadap anion yang menyebabkan perbedaan panjang gelombang.

Al-Kimia | Volume 5 Nomor $22017 \mid 141$ 


\section{Uji Limit Deteksi Zat Warna Kayu Sappang (Brazilin) Sebagai Sensor Anion Sianida}

Berdasarkan hasil uji ionochromic, zat warna kayu sappang (brazilin) dapat dimanfaatkan sebagai sensor anion sianida maka dilakukan uji lebih lanjut untuk mengetahui limit deteksi dengan menggunakan pengukuran UV-Vis.

Berdasarkan hasil pengukuran dengan analisis UV-Vis, zat warna kayu sappang (brazilin) dalam pelarut metanol (Gambar 5) berinteraksi dengan anion sianida dengan nilai ekuivalen 3 $\left(3 \times 10^{-4} \mathrm{M}\right)$ yang memiliki pergeseran batokromik dengan panjang gelombang dari $360 \mathrm{~nm}$ menjadi $500 \mathrm{~nm}$. Pergeseran menyebabkan terjadinya perubahan warna dari warnaorange menjadi warna merah keunguan (Gambar 6). Sedangkan pada pelarut aseton apabila diinteraksikan dengan anion sianida yang memiliki nilai ekuivalen sebesar $\left(1 \times 10^{-4} \mathrm{M}\right)$ terhadap senyawa tersebut. Pergeseran panjang gelombang sebesar $380 \mathrm{~nm}$ dengan absorbansi 0,723 menjadi $580 \mathrm{~nm}$ dengan absorbansi 0.974. Berdasarkan Gambar 7(a) dan 7(b) terlihat bahwa kenaikan anion sianida meningkatkan absorbansi. Absorbansi dipengaruhi oleh konsentrasi anion, berdasarkan data yang diperoleh menunjukkan bahwa kenaikan absorbansi disebabkan oleh kenaikan konsentrasi anion (terjadi deprotonasi seperti Gambar 7).

Salah satu faktor yang mempengaruhi interaksi anion terhadap senyawa sensor yaitu pelarut metanol merupakan pelarut protik yang memilki gugus hidroksi sehingga apabila anion diinteraksikan dengan senyawa sensor yang dilarutkan dalam metanol maka akan terjadi persaingan antara pelarut dan senyawa sensor terhadap anion. Pelarut tersebut dapat mensolvasi senyawa sensor sehingga mengalami perbedaan panjang gelombang dan absorbansi dengan aseton.

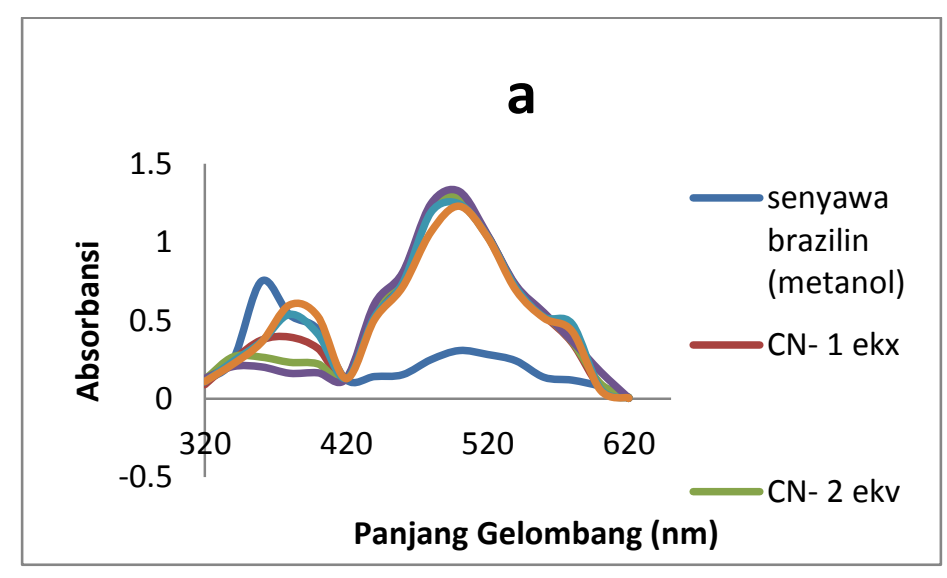

Al-Kimia | Volume 5 Nomor $22017 \mid 142$ 


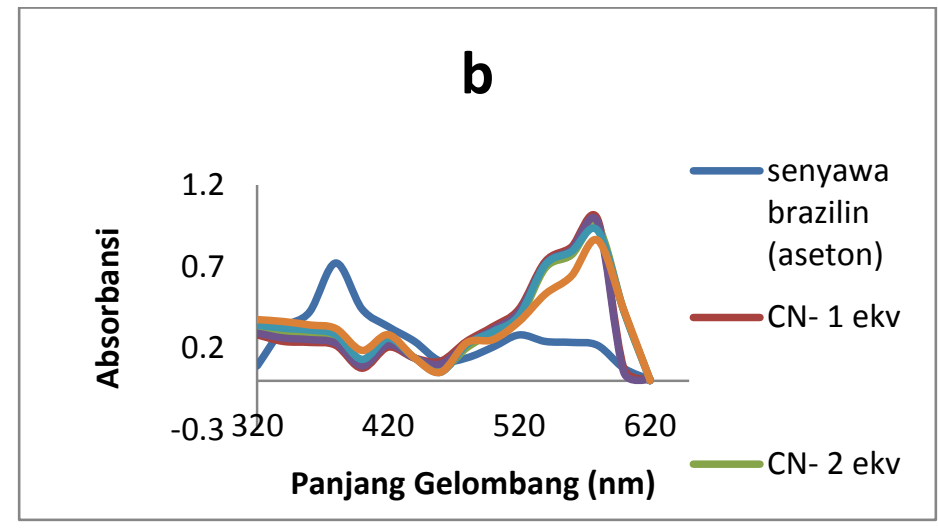

Gambar 7. Interaksi zat warna kayu sappang (brazilin) dengan anion sianida dalam pelarut metanol (a) dan pelarut aseton (b).

\section{Penutup \\ Kesimpulan}

Hasil uji sensor anion menunjukkan bahwa zat warna K. Sappang (brazilin) mengalami perubahan warna pada anion fosfat, anion asetat, anion nitrit, anion karbonat, anion sianida dan anion hidroksil. Pelarut metanol memberikan uji positif terhadap zat warna tersebut terhadap anion sianida, zat warna kayu sappang (brazilin) berinteraksi dengan anion sianida dengan limit deteksi $3 \times 10^{-4} \mathrm{M}$ yang memiliki pergeseran batokromik dengan panjang gelombang dari $360 \mathrm{~nm}$ menjadi $500 \mathrm{~nm}$. Pada pelarut aseton zat warna kayu sappangdengan anion sianidamemiliki limit deteksi $1 \times 10^{-4}$ M. Pergeseran panjang gelombang sebesar $380 \mathrm{~nm}$ menjadi $580 \mathrm{~nm}$.

\section{Ucapan terima kasih}

Pada kesempatan ini kami ucapkan terima kasih yang sebesar-besarnya kepada Direktorat Riset dan Pengabdian Masyarakat - Direktorat Jenderal Penguatan Riset dan Pengembangan Kementerian Riset, Teknologi, dan Pendidikan Tinggi Republik Indonesia yang telah memberikan bantuan dana penelitian, Bapak pembina dan ketua YPI Mega Rezky, ketua STIKes Mega Rezky, LPPM, Laboratorium Prodi Analis Kesehatan dan Farmasi STIKes Mega Rezky Makassar, Laboratorium Terpadu Jurusan Kimia Universitas Hasanuddin dan Laboratorium Politeknik Akademi Teknik Industri Makassar, terima kasih atas bantuan dan pengarahannya dalam penelitian ini.

\section{DAFTAR PUSTAKA}

Afkhami, A. \& Nahid, S. (2007). A novel cyanide sensing phase based on immobilization of methyl violet on a triacetylcellulose membrane, Sensor and Actuator B, 122 (2) 437-441. 
Alghiri, D. (2010), Sintesis turunan chalcone dari vanilin dan potensi penggunaannya sebagai indikator titrasi asam basa dan sensor anion, Tesis, Jurusan Kimia FMIPA UGM, Yogyakarta.

Indriani, H. (2003). Stabilitas pigmen alami kayu secang (caesalpinia sappan linn.) dalam model minuman ringan. Skripsi. Institut Pertanian, Bogor.

Marini, V., G., Torri, E., Zinmermann, L., M., \& Machadoa, V., G. (2010). Anionic chromogenic chemosensor based on 4-(4-nitrobenzylideneamine)-2,6-diphenylphenol for selective detection of cyanide in acetonitrile-water mixture, ARKIVOC, 11, 146-162.

McDonagh, C., Burke, C.S. \& Mac.Craith, B.D. (2008). Optical chemical sensors, Chem. Rev., 108(2), 400-422.

Reichardt, C. (1994). Solvatochromic dyes as solvent polarity indicators, Chem. Rev., 94 (8), 2319-2358.

Satheshkumar, A., Mossalamy, E.H., Manivannan, R., Parthiban, C., Al-Harbi, L. M., Kosa, S., ... Elango, K.P. (2014) Anion induced azo-hydrazone tautomerism for the selective colorimetric sensing of fluoride ion, Spectrochim. Acta, Part A, 128, 798-805.

Timberlake, C.F. \& Bridle P. (1983). Anthocyanins. di dalam J. Walford (ed). Developments in Food Colours. London, Applied Science Publishers LTD.

Xu, Z., Chen, X., Kim, H. N., \& Yoon, J. (2010). Sensor for the optical detection of cyanide ion, Chem. Soc. Rev., 39(1), 127-137.

Zhang, C., \& Suslick, K., S. (2005). A colorimetric sensor array for organics in water, J. Am. Chem. Soc., 127(33), 11548-11549. 